\title{
Making climate instruments work for sustainable transport in developing countries
}

\author{
Stefan Bakker and Cornie Huizenga
}

\begin{abstract}
In order to meet long-term climate change mitigation objectives, emissions cuts are required in all regions across the globe and in all sectors, including transport. In financing this effort, the Clean Development Mechanism (CDM) and the Global Environmental Facility $(G E F)$ are until now the only international climate policy instruments under the United Nations Framework Convention on Climate Change that provide incentives for emissions reductions in developing countries. More recently, the Clean Technology Fund (CTF) was established. In this paper, we show that the impact of these financing instruments on transport has been very limited, due to methodological difficulties, a data-intensive monitoring process and the limited funding available. We argue that the transport sector is not likely to play a significant role in the continuation of a carbon credit offsetting scheme, unless these methodological requirements are simplified and significantly more funding is available.

In the post-2012 climate regime, there may be substantial international funding available in addition to existing credit schemes and international funds, which could be channeled through nationally appropriate mitigation actions (NAMAs). This can provide new and better opportunities for sustainable transport in developing countries. We propose a framework for NAMAs, including types of policies and measures, measurement, reporting and verification of the actions, and an institutional and financial structure. We conclude that climate funding needs to be aligned closely with domestic and multilateral development finance flows in order to make a difference for sustainable transport.
\end{abstract}

Keywords: Transport; Climate mechanisms; NAMAs; MRV; CDM; Climate finance; Developing countries.

\section{Transport and climate change}

In 2004, the transport sector accounted for $6 \mathrm{GtCO}_{2}$-eq or $13 \%$ of global greenhouse emissions (Metz et al., 2007). Taking into account the effect of ozone and aerosols, the transport sector is estimated to have contributed $9 \%$ to the increase in global mean temperature up to the year 2000 since pre-industrial times, with $\mathrm{CO}_{2}$ and ozone being the most significant warming emissions, partly offset by cooling aerosols from shipping (Skeie et al., 2009). Unger et al. (2010) also attribute the largest radiative forcing contribution up to 2020 to road transportation, with an important part of that caused by black carbon. IEA/OECD (2009) projects transport emissions to rise by over $80 \%$ by 2050 in a business-as-usual scenario.

Although current per capita transport emissions in developing countries are relatively low compared to OECD

Stefan Bakker is at the Energy Research Centre of the Netherlands, Department of Policy Studies. E-mail: bakker@ecn.nl

Cornie Huizenga is with the Partnership on Sustainable Low Carbon Transport and the Asian Development Bank. E-mail: cornie.huizenga@slocatpartnership.org countries, close to $90 \%$ of the increase is expected to take place in developing countries, mostly from private vehicles and freight (IEA/OECD, 2009). In order to meet the greenhouse gas (GHG) stabilization target of 450 ppmv, global GHG emissions need to be reduced by more than $50 \%$ compared to current levels, by 2050 (Metz et al., 2007). To achieve this, mitigation efforts in all sectors, including transport, are required in both developed and developing countries (IEA/OECD, 2009). It is now understood that in the case of a 450 ppmv scenario, developing countries as a group would have to accomplish a reduction of $15-30 \%$ below business-as-usual by 2020 , (den Elzen and Höhne, 2008; Karousakis, 2008).

In the ASIF framework (Schipper et al., 2000) often used in transport system modelling, emissions are a product of Activity (A), or the demand in person or tonne-kilometres; Modal shares (S); Energy intensity (I) of each mode; and the Carbon content of the fuel (F) used in each mode.

Substantially changing the rising emissions trend will require the adoption of a range of available and new technologies as well as a change in travel patterns (IEA/ OECD, 2009; Metz et al., 2007; Wright and Fulton, 2005). The "Avoid-Shift-Improve" approach (ADB and CAI-Asia, 
Table 1. ASI framework and examples of policy instruments

\begin{tabular}{|c|c|c|c|c|}
\hline & Planning & Economic & Regulatory & Soft \\
\hline A & Mixed-high density planning & Road pricing / congestion charge & Closing districts to vehicles & Campaigning for locally produced goods \\
\hline $\mathrm{S}$ & $\begin{array}{l}\text { Mass transit / NMT } \\
\text { infrastructure }\end{array}$ & Incentives for Mass transit / NMT & & $\begin{array}{l}\text { Awareness raising for Mass } \\
\text { transit/NMT/ car-pooling }\end{array}$ \\
\hline I & & $\begin{array}{l}\text { Incentives for efficient / } \\
\text { low-carbon vehicles and fuels }\end{array}$ & $\begin{array}{l}\text { Fuel economy standard / target } \\
\text { for low carbon fuels and } \\
\text { vehicles }\end{array}$ & Eco-driving training campaigns \\
\hline ASI & Integrated transport planning & Fuel/carbon tax & Sectoral emissions target & $\begin{array}{l}\text { Institutional restructuring in support of } \\
\text { integrated transport planning }\end{array}$ \\
\hline
\end{tabular}

NMT: non-motorized transport.

Source: Authors' elaboration.

2010) builds on ASIF and implies that policies to limit GHG emissions in the transport sector will have to consist of a combination of measures aimed at: (a) avoiding the need to travel, e.g. by the integration of land use and transport policies; (b) shifting travel to the most efficient mode, which in most cases will be either non-motorized or public transport for passenger transport and to rail or water transport for freight; and (c) improving existing forms of transport through technological improvements to make engines and fuels less carbon intensive.

Transport policy instruments can try to influence each of these components by, for example, reducing the demand with improved spatial planning, shifting to public transport, improving engine technology and using electric vehicles. In order to achieve the large emissions reduction potential in both passenger and freight transport, strong policy packages are required that cover both the technological and behavioural aspects (e.g. Johansson, 2009; IEA/OECD 2009; Chapman, 2007). Policy instruments can be differentiated into planning, economic, regulatory and "soft"1 (Wittneben et al., 2009). Table 1 gives examples of how these instruments can be related to the Avoid-Shift-Improve strategies.

Such policies may have strong national or local co-benefits in terms of air quality, energy supply security, reduced congestion, livable cities, local employment and improved health (Nemet et al., 2010; Huizenga et al., 2008; IEA/OECD, 2009). In fact, many of the transport policies and interventions are being pursued with the primary goal being those benefits, and in those cases, the GHG reduction can also be seen as a co-benefit. The challenge, therefore, is to promote transport policies that foster national sustainable development and global benefits with respect to GHG emissions reduction.

This is particularly relevant to developing countries, which do not face a binding emissions target under the Kyoto Protocol. Considering the state of affairs in the international climate negotiations, it is unlikely that they will adopt such targets in the period up to 2020 (UNFCCC, 2009b; 2010a), although some countries have taken on

\footnotetext{
${ }^{1}$ These can include institutional strengthening, capacity-building or awareness-raising and training.
}

national targets on a voluntary basis, such as Costa Rica, Indonesia, Singapore and South Korea (UNFCCC, 2010b). Developing countries are, however, in the future supposed to undertake nationally appropriate mitigation actions (NAMAs) in order to contribute to global mitigation of GHGs (UNFCCC, 2007; 2009b).

In this paper, we assume that reducing GHG emissions from transport is a voluntary action for developing countries, which, based on the global benefit, is in principle eligible to receive support from developed countries. While the detailed nature of emissions reduction activities will vary between countries reflecting their unique characteristics, the supporting mechanisms under the United Nations Framework Convention on Climate Change (UNFCCC) are expected to be the same for all developing countries. Therefore, in this paper we treat them as one group, in line with their treatment under the UNFCCC. When more is known about the mechanisms, more attention to their implementation in different contexts, for example least developed countries, could be necessary.

This paper aims to provide recommendations on how international support, in particular for supported NAMAs, can spur low carbon sustainable transport in developing countries. We analyse how the existing climate instruments are working for the transport sector (section 2). Section 3 provides a preliminary analysis, partly based on four case studies $^{2}$ of options for transport policies and measures under emerging or future instruments, focusing on NAMAs. In the final section, we provide conclusions and recommendations.

\section{Transport under existing international climate mechanisms}

In this section, we provide an overview of the extent to which the main existing international climate instruments

\footnotetext{
2 The four case studies include: (a) Optimization of conventional bus system in Mexico, by Ecofys; (b) Comprehensive mobility strategy, Belo Horizonte, Brazil by EMBARQ, WRI Institute for sustainable transport; (c) Travel demand management in Jakarta, Indonesia by the Transport Research Laboratory; (d) The use of standardized base lines for transport, Hefei, China by the Wuppertal Institute.
} 
Table 2. Transport projects in the CDM pipeline, July 2010

\begin{tabular}{|c|c|c|c|c|}
\hline \multirow[t]{2}{*}{ Transport sub-type } & \multirow[t]{2}{*}{ Additional info } & \multirow[t]{2}{*}{ Methodology } & \multirow[t]{2}{*}{ No. of projects / PoAs } & \multirow{2}{*}{$\frac{\text { Emissions reduction }}{\mathrm{ktCO}_{2} / \mathrm{yr}}$} \\
\hline & & & & \\
\hline Biodiesel from waste oil & & AM47 / ACM17 & 1 & 226 \\
\hline Biodiesel for transport & & AMS-III.T./ACM17 & 5 & 495 \\
\hline Bus Rapid Transit (BRT) & & AM31 / ACM16 & 11 & 1467 \\
\hline Cable cars & & AMS-III.U. & 1 & 17 \\
\hline Metro: efficient operation & & AMS-III.C. & 1 & 16 \\
\hline Mode shift: road to rail & Freight and passenger & AMS-III.C. / ACM16 & 3 & 688 \\
\hline Rail: regenerative braking & & AMS-III.C. & 3 & 112 \\
\hline Motorbikes & Electric bikes & AMS-III.C. & 4 & 130 \\
\hline Scrapping old vehicles & PoA & AMS-III.C. & 1 & 3 \\
\hline Total & & & 30 & 3153 \\
\hline
\end{tabular}

A(C)M: approved (consolidated) methodology; AMS: approved small-scale methodology.

Source: UNEP/Risø (2010).

have addressed the transport sector in developing countries. These instruments include the Clean Development Mechanism, the Global Environmental Facility and the Clean Technology Fund. ${ }^{3}$

\subsection{Clean Development Mechanism}

The Clean Development Mechanism (CDM) is an arrangement under the Kyoto Protocol allowing developed countries with a greenhouse gas reduction commitment to invest in project activities that reduce emissions in developing countries as an alternative to emissions reductions in their own countries. In addition to this, the CDM aims to contribute to sustainable development in developing countries (UNFCCC, 2005). Proposed projects have to use a baseline and monitoring methodology, reviewed by a Methodology Panel and approved by the CDM Executive Board to show how the certified emissions reductions (CERs) are derived. Once registered with the CDM Executive Board, a project can generate CERs on an annual basis for a maximum of 21 years, resulting in annual revenues based on the prevailing CER price at the time a contract is drawn up. Another crucial feature of an approved CDM project is that it has demonstrated that the planned reductions would not occur without the additional incentive provided by emissions reductions credits, a concept known as "additionality" (UNFCCC, 2005). Since 2005, larger numbers of similar small-scale activities can be developed under one umbrella as a CDM Programmes of Activities (PoA).

To date, the transport sector has played a very limited role in the CDM. As of July 2010, 30 out of 5,312 projects in the pipeline are related to transport (including biofuels) (UNEP/Risø, 2010). Out of these 30 projects only 2 are

\footnotetext{
3 There are other international climate funding mechanisms that can support climate protection activities for the transport sector, for example the German Climate Initiative. Their scale is more limited than GEF, CDM and CTF, which is why they are not included in the analysis in this paper.
}

registered. The pipeline includes all projects and PoAs that are under validation by an operational entity, have been validated, are registered by the CDM Executive Board, or are requesting registration. Together, the current 30 transport projects are expected to reduce $3.2 \mathrm{MtCO}_{2}-\mathrm{eq} / \mathrm{yr}$ up to 2012 , or $0.4 \%$ of the total reductions of the current pipeline. Table 2 shows the transport projects broken down by approved methodology.

Compared to its share in global emissions, the transport sector is highly underrepresented. A first explanation lies in the fact that across the globe, transport sector emissions are found difficult to abate, and most countries first look at "low-hanging fruit" in other sectors in order to meet climate objectives (Barías et al., 2005). The low share of transport projects in CDM can also be explained by the following barriers (adapted from ADB and CAI-Asia 2010; MillardBall and Ortolano, 2010): difficulty in determining additionality, e.g. due to the small share of CER revenues in the total project $\operatorname{cost}^{4}$ and the fact that mitigation actions in the transport sector can be implemented for a multitude of reasons; difficulty in establishing the baseline scenario, due to the fact that a multitude of scenarios can be made plausible; complexity in designing methodologies and modelling tools appropriate for the CDM, including, for example, rebound effects; lack of data required to apply the methodologies; emissions from individual sources are relatively small and dispersed, making monitoring difficult and costly; lack of uniformity in Methodology Panel recommendations; and, specifically for biofuels: difficulty in determining life cycle emissions.

These barriers help explain the fact that few methodologies have been approved in the transport sector since 2005 when the first CDM methodology was approved,

\footnotetext{
${ }^{4}$ CERs will often only cover a few per cent of the investment costs of infrastructure projects such as BRTs. Therefore, in general, it can be said for transport projects that climate mitigation is only one of the considerations and often of lesser importance than congestion reduction or air quality improvement.
} 
although a larger number have been proposed in recent years (Millard-Ball and Ortolano, 2010). In addition, experience has shown that applying approved methodologies has been difficult, e.g. for BRT projects using AM31, which was approved in 2006, and biodiesel from waste fats using AM47 (approved in 2007). In late 2009, these methodologies have been consolidated in ACM16 and ACM17, which are used by three and four projects, respectively, as of July 2010.

The recent recommendations on priorisation for transport CDM projects by the CDM Executive Board (UNFCCC, 2009d) and the increase in approved methodologies can be seen as a sign that there is scope for more transport projects in the CDM. However, the CDM, in general, is now being criticized for including projects that would have happened anyhow (i.e., non-additional projects, Bakker et al., 2010a), and transport projects are among those having problems demonstrating additionality (Millard-Ball and Ortolano, 2010).

\subsection{Global Environment Facility (GEF)}

The GEF provides grants to developing countries to address global environmental issues, including climate change, on the basis of the agreed full incremental cost ${ }^{5}$ and is used by the UNFCCC as its financial mechanism. In 2000, the GEF Council approved Operational Program \#11 (OP 11 "Promoting Environmentally Sustainable Transport"), a programme aimed at enhancing efforts in the transport sector. As of April 2009, the GEF had funded 37 transportation projects in more than 73 cities. Initially, GEF support to the transport sector focused on technological solutions. However, GEF-4 (2006-10) emphasizes "nontechnology" options, such as planning, modal shift to lowGHG-intensive transport modes and the promotion of better managed public transit systems. The strategic programme on "sustainable innovative systems for urban transport" prioritizes countries with rapidly growing cities, which includes urban planning, public transport investments (particularly bus rapid transit (BRT)), transport demand management (TDM) and national policy development (GEF, 2009a).

During this period, out of a total replenishment of US\$ 3.1 billion, ${ }^{6}$ the GEF has allocated approximately US\$ 201 million to sustainable urban transport projects, with an average of US\$ 5.4 million per project. This funding has leveraged more than US\$2.47 billion in co-financing. This co-financing ratio of 1 to 12.3 is the highest in all GEF programmes as it often requires large-scale investments to develop infrastructures. Figure 1 shows that the portfolio is quite diverse, with substantial investments in BRT, vehicles and non-motorized transport (NMT) ("other" refers to capacity-building, planning, awareness-raising and policymaking).

\footnotetext{
5 Article 4.3, UNFCCC; Bongardt et al. (2009).

${ }^{6} \mathrm{http} / / /$ www.thegef.org/gef/replenishment4

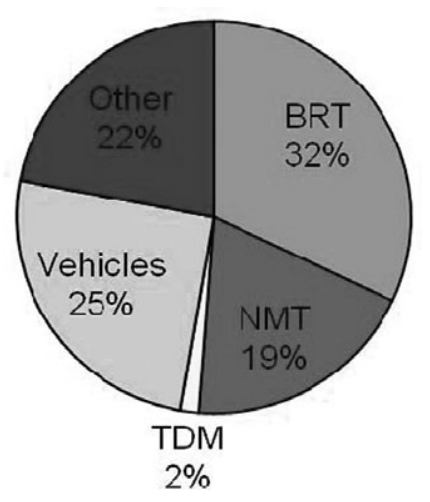

Figure 1. GEF Transport funds breakdown. Source: Replogle and Hook (2010).

Estimating these projects' impact on $\mathrm{CO}_{2}$ emissions is difficult (GEF, 2009a). Project documents indicate an expected direct $\mathrm{CO}_{2}$ reduction of $31.5 \mathrm{MtCO}_{2}$ over the lifetime of the projects, and an expected indirect $\mathrm{CO}_{2}$ reduction of $34.5 \mathrm{MtCO}_{2}$. The methodologies for calculating these emissions reductions used by the different projects are diverse and not strictly comparable.

The GEF-5 programme (2011-15) will aim to further increase the focus on integrated transport planning, and will place more emphasis on local environmental and social benefits (GEF, 2009b). In particular, it will provide support for the development of sustainable transport and urban policy and regulatory frameworks. Also, greater attention will be given to measuring and quantifying global environmental benefits; outcome indicators will include the number of cities adopting sustainable transport and urban policies and regulations, the volume of investment mobilized, and tonnes of $\mathrm{CO}_{2}$ equivalent avoided.

A methodology specifically for estimation of the impact on GHG emissions of GEF transport interventions is being developed. This methodology will complement the methodology for energy efficiency and renewable energy projects (GEF, 2008). ${ }^{7}$ Particular to the GEF GHG assessment methodology is the distinction between: (a) direct emissions reductions; (b) post-project direct emissions reductions; and (c) replication and indirect emissions reductions.

\subsection{Clean Technology Fund ${ }^{8}$}

In July 2008, the Climate Investment Fund was established by the World Bank in cooperation with other multilateral

\footnotetext{
${ }^{7}$ An expert meeting was held 17-19 February 2010, organized by the Scientific and Technical Advisory Panel of GEF and the Asian Development Bank. See Replogle and Hook (2010) for an overview of the suggested contours of the GEF Transport methodology. An important recommendation of the expert meeting was to consider the use of default factors to predict the emissions reduction effects of certain transport interventions. The transport methodology is expected to be available by the end of 2010 and will include use of default factors as recommended by the expert meeting (Personal communication with Lev Neretin, GEF-STAP).

${ }^{8}$ This section is based on World Bank (2008) unless otherwise mentioned.
} 
Table 3. Transport components under the Clean Technology Fund, March 2010.

\begin{tabular}{|c|c|c|c|c|c|}
\hline Country & $\begin{array}{l}\text { Total investment } \\
\text { cost transport } \\
\text { component } \\
\text { (million \$) }\end{array}$ & $\begin{array}{l}\text { Total size CTF } \\
\text { allocation } \\
\text { (million \$) }\end{array}$ & $\begin{array}{l}\text { Transport CTF } \\
\text { allocation } \\
(\text { million } \$)\end{array}$ & Transport components & $\begin{array}{l}\text { Emissions reductions } \\
\text { from transport } \\
\text { component } \\
\left(\mathrm{MtCO}_{2}-\mathrm{eq} / \mathrm{yr}\right)\end{array}$ \\
\hline Egypt & 865 & 300 & 100 & BRT; light rail transit and rail links; clean technology bus & 1.5 \\
\hline Morocco & 800 & 150 & 30 & BRT; tramway; light rail & 0.54 \\
\hline Mexico & 2,400 & 500 & 200 & $\begin{array}{l}\text { Modal shift to low carbon alternatives (BRT); promotion } \\
\text { of low carbon bus technology; capacity building }\end{array}$ & 2.0 \\
\hline Thailand & 1,267 & 300 & 70 & BRT Corridors & 1.16 \\
\hline Philippines & 350 & 250 & 50 & BRT Manila - Cebu; institutional Development & $0.6-0.8$ \\
\hline Viet Nam & 1,150 & 250 & 50 & Enhancement urban rail & 1.3 \\
\hline Colombia & 2,425 & 150 & 100 & $\begin{array}{l}\text { Implementation of integrated public transit systems; } \\
\text { scrapping of old buses; introduction of low-carbon bus } \\
\text { technologies in the transit systems }\end{array}$ & 2.8 \\
\hline Total & 9,257 & 1,900 & 600 & & $9.9-10.1$ \\
\hline
\end{tabular}

Source: http://www.climateinvestmentfunds.org; full country investment plans available.

development banks (MDBs). Two strategic funds were set up under the CIF: the Clean Technology Fund (CTF) and the Strategic Climate Fund. The CTF is designed to fill an immediate financing gap before further details of the future climate regime are worked out and aims to provide scaled-up financing for "transformational actions" that contribute to the demonstration, deployment and transfer of low-carbon technologies with a significant potential for long-term greenhouse gas (GHG) emissions savings.

The CTF utilizes a range of concessional financing instruments, such as grants and concessional loans, and risk mitigation instruments, such as guarantees and equity. For the transport sector, measures which the CTF support may include: modal shift to low carbon public transportation in major metropolitan areas, with a substantial change in the number of passenger trips by public transport; modal shift to low-carbon freight transport, with a substantial change in tonnage of freight moved by road transport to rail; improvement of fuel economy standards and fuel switching; and deployment of electric and hybrid (including plug-in) vehicles.

As of March 2010, twelve country investment plans have been approved by the CTF: Egypt, Morocco, Mexico, Thailand, Philippines, South Africa, Turkey, Colombia Indonesia, Kazakhstan, Ukraine and Viet Nam, and one regional investment plan for the North African region. Transport is included in seven plans, all in the realm of public transport, particularly BRT, see Table 3. The total required investment for these measures was estimated to be US\$ 9.3 billion. The CTF funding for the transport measures adds up to US\$ 600 million and the estimated annual emissions reduction to about $10 \mathrm{MtCO}_{2}$ per annum (CTF, 2010).

The CTF investment plans are approved by the Trustfund Committee without having been submitted to an external expert panel for the validation of the emissions reductions. In its assessment, the Trustfund committee takes into account the potential transformational impacts of the proposed actions and considers criteria such as GHG reduction potential, demonstration and upscaling potential, development impact, and additionality of CTF funding (CTF, 2009a). Of specific importance is the potential contribution of the project to the transformation of the sector and the related demonstration and upscaling potential. The specific methodological guidelines on how to calculate the GHG reduction potential are outlined in CTF (2009b). An important difference with the GEF is that this methodology is not applied at the time of the initial approval of the investment programme but only at the time of detailed project design. ${ }^{9}$ Project developers are free to decide what specific methodology they use to assess the GHG emissions avoided by the project at the time of the initial approval of the country investment programme.

For the future, CTF aims to use guidelines, partly transport-specific, for assessing the results of its investments and tracking the fulfillment of its objectives (CTF, 2009b). A three-tiered approach is being recommended by the CTF for monitoring. One tier to be monitored is the transformational impacts of the CTF. This tier consists of indicators that demonstrate the extent to which CTF co-financing catalyzes lasting changes in the structure or function of sub-sectors, sectors or markets. The second tier is the country outcomes indicators, which measure aggregate country outcomes and global trends relevant to the CTF's objectives. The third tier is monitoring the CTF's contributions to country outcomes. This tier consists of indicators covering the CTF's contributions to country outcome indicators at three different levels: country: the preparation of country CTF Investment Plans will be monitored to measure progress in providing support for climate actions in country-led development processes; portfolio performance: these consist

\footnotetext{
${ }^{9}$ Since none of the transport components has reached the phase of review of detailed design by the trust fund committee, no experience exists with the application of the CTF GHG assessment methodology.
} 
Table 4. Overview of transport projects in existing climate instruments

\begin{tabular}{lrrrr}
\hline & $\begin{array}{r}\text { Year of } \\
1^{\text {st }} \text { project }\end{array}$ & $\begin{array}{r}\text { No. of } \\
\text { Projects }\end{array}$ & $\begin{array}{r}\text { Funding } \\
{[\$ \text { million }]}\end{array}$ & $\begin{array}{r}\text { Reported/expected } \\
\text { emissions reductions } \\
{\left[\mathrm{MtCO}_{2} \text {-eq/yr }\right]}\end{array}$ \\
\hline CDM & 2006 & $30^{\mathrm{a}}$ & 672 (CERs) & 3.2 \\
GEF-4 & 2006 & 37 & 201 (grants) & $3.2^{\mathrm{c}}$ \\
CTF & 2009 & 7 & 600 (loans) & $10^{\mathrm{d}}$
\end{tabular}

${ }^{a}$ in pipeline (registered, requesting registration and at validation);

${ }^{\mathrm{b}}$ expected total undiscounted revenues at 10 \$/CER, 3x7 years crediting, excluding transaction cost;

${ }^{\mathrm{c}}$ direct impact, assuming 10 years lifetime;

$\mathrm{d}$ assuming a life time of 10-20 years depending on type of investment Source: Authors' elaboration.

of indicators to measure the MDBs' portfolio quality and organizational efficiency; and project outputs, which measure the CTF's effectiveness in achieving its objective of scaling up low carbon technologies.

Table 4 provides an overview of the impact of investments from climate mechanisms on the transport sector. It appears the CTF, in its short history, has made a bigger impact in developing projects to reduce transport emissions than has the CDM and the GEF, which have been operational for a longer period of time. The overview also shows that the impact of climate instruments is currently rather limited, i.e. approximately $16 \mathrm{MtCO}_{2}$-eq/yr, as compared to the transport emissions in developing countries of approximately 3,100 $\mathrm{MtCO}_{2}$-eq/yr in 2005 (IEA/OECD, 2009). Therefore, current climate mechanisms can only be expected to play a limited role in achieving a $15-30 \%$ reduction deviation from the baseline for all GHG emissions by 2020 . The overall funding made available of US\$ 1.4 billion is limited as well considering the size of the transport sector.

\section{Applicability of new mechanisms for transport}

This chapter gives an overview of the potential of emerging climate instruments for fostering a significant shift towards low-carbon transport in developing countries. This analysis is preliminary, considering the yet unknown existence of these mechanisms in the future or their detailed features. We review CDM, sectoral crediting and NAMAs. ${ }^{10}$

\subsection{Future of the $C D M$}

The first commitment period of the Kyoto Protocol runs until 2012. Although, as of March 2010, no formal agreement was reached on a new commitment period after 2012, there is widespread consensus in the UNFCCC that there will be a role for the CDM post-2012. The discussions

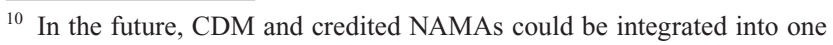
instrument.
}

(C) 2010 The Authors. Natural Resources Forum (C) 2010 United Nations on what this role should be and possible changes to the design of the CDM post-2012 are taking place mainly in the Ad Hoc Working Group on Further Commitments under the Kyoto Protocol (AWG-KP) (UNFCCC, 2009c). At COP15 in Copenhagen, some decisions to amend the CDM were adopted, most notably ones to prioritize baseline methodologies for underrepresented sectors. Also, a request to the Subsidiary Body for Scientific and Technological Advice was made to recommend modalities and procedures for the development of standardized baselines (UNFCCC, 2009c).

In the following section, we discuss how emerging developments such as Programmes of Activities, a standardized baseline and possible future changes, as discussed in the AWG-KP, may affect the prospects for the transport sector compared to the current situation. For a more elaborate description of these changes, see Bakker et al. (2010a), on which the assessment below is partly based.

\subsubsection{Further strengthening Programmes of Activities}

Currently similar project activities using one baseline and monitoring methodology can be developed under a PoA. This may improve conditions for transport to some extent, e.g. if 10 BRTs in a country are combined this could reduce the uncertainty and transaction cost related to additionality demonstration and application of the baseline methodology. If different types of activities would be eligible under a PoA as well, this would further enhance opportunities, particularly for "mixed strategies" in which different kinds of activities of an integrated sustainable transport strategy relating to, for example, fuels, vehicle technologies, public and non-motorized transport, are combined. Data availability and quality will be a constraining factor, however, in the case of a PoA approach.

\subsubsection{Standardized baselines}

Baselines can be pre-determined based on a benchmark for a particular type of activity for a particular geographical area. Standardized baselines are often mentioned in the context of the industry or power sector, in which an emissions benchmark can be expressed per unit of product. Performance benchmarks and emissions intensity values are already used within the CDM, e.g. in the power sector. For the transport sector, standardized baselines may also be applicable, however, there are no concrete proposals as of yet. Possible examples mentioned include modal splits, occupancy rates and emissions per unit of travel (Bongardt et al., 2009; TRL, 2010), particularly for specific vehicle fleets such as taxis, buses or rail systems. If standardized baselines could be developed and applied successfully, this would significantly reduce the methodological and possibly the data-related problems that transport-CDM projects currently face. However, developing broadly applicable baselines is likely to be a challenge due to the considerably 
different circumstances under which taxis or buses operate in different cities. ${ }^{11}$ The increased upfront burden of necessary data collection costs to construct performance standards or define adequate default values for standardized baselines is not to be underestimated either, even if transaction costs at the project level would be reduced in the long run.

\subsubsection{CER discounting}

Discounting is the application of a reduction factor to the emissions reductions achieved in a project: 1 tonne of $\mathrm{CO}_{2}$-eq reduced results in less than 1 CER. CER discounting is sometimes mentioned in the context of $\mathrm{N}_{2} \mathrm{O}$ and HFC-23 destruction projects, which are cheap and easy to implement actions, yielding a large amount of CERs. Other arguments mentioned in support of CER discounting are to create a mechanism with overall net atmospheric benefits rather than pure offsetting or the possibility to differentiate according to the contribution to sustainable development. If the CERs from transport projects were to be discounted less (or not at all) compared to other project types, the transport sector would improve its comparative position. ${ }^{12}$ The key difficulty for CER discounting is the political feasibility of establishing the discount factors.

\subsubsection{Allocated demand}

Credit buyers can be required to procure a certain portion of their demand for CERs to certain sectors. If this can be done for the transport sector it will greatly improve its opportunities. It will stimulate development of transportCDM projects, but achieving the required supply of successful projects may still be a challenge. In addition, this is a politically difficult differentiation option.

\subsubsection{Co-benefits}

The contribution of the CDM to sustainable development in the host countries has been limited (Olsen and Fenhann, 2008). Under the current rules, only the host country may assess the sustainable development contribution, with no role for the validator or the CDM Executive Board. In order to improve the sustainability profile of the CDM, explicitly recognizing sustainable development benefits by setting a threshold has been suggested and adding a required evaluation by the validator and/or the Executive Board. As many transport projects have very strong co-benefits, e.g. for air quality, reduced congestion, energy security and social equality (e.g. ADB and CAI-Asia, 2010; CCAP, 2010; Nemet et al., 2010), the transport sector is likely to benefit from such an approach. However, this undermines the prerogative of developing countries to assess projects

\footnotetext{
${ }^{11}$ One possibility might be to define a limited number of representative operating conditions for which standardized baselines can be formulated.

12 The main difficulty with transport projects, i.e. methodological complexity, will not be addressed by this option.
}

against their own sustainable development criteria and is something that may not be politically feasible. Another possibility would be to apply CER discounting to projects with no or few demonstrated co-benefits.

\subsubsection{Positive list}

Project types on a positive list are deemed automatically additional and thus exempted from additionality testing. Since demonstrating additionality is often very difficult for transport sector projects, this could improve their prospects. However, the reason for this difficulty is that there are many objectives other than climate mitigation involved in the undertaking of an activity and the CER contribution to overall profitability is relatively low. It is hard to imagine that many transport sector project types will be included in a positive list (Bongardt et al., 2009).

\subsubsection{Sectoral CDM}

Taking the CDM from the level of a project-based instrument to the level of programmes (as is done in PoAs) or sector policies could enhance the opportunities for transport, particularly by the possibility to scale up efforts that are now taken on a case-by-case basis. Examples of eligible activities would be land-use planning, voluntary agreements for energy efficiency, a congestion charge, or eco-driving training. However, the methodological complexities and uncertainties are not likely to be reduced (Wittneben et al., 2009).

\subsubsection{Summary}

This section has shown that several possible changes to the CDM may improve conditions for the transport sector by simplifying methodologies, demonstration of additionality, and reducing the data needs. In addition, a broader application of the existing approved methodologies may also have a beneficial impact for the transport sector. At the end of the day, much depends on the total demand for CERs post-2012. Many developed countries see a limited role for the CDM, focusing mostly on the least developed countries, with other instruments (see below) and domestic actions becoming more important for the more advanced developing countries (e.g. CEC, 2009). If the CDM market is indeed limited in size, it is not likely that it can play a significant role for the transport sector.

\subsection{Sectoral crediting approaches}

Discussions on a possible sectoral crediting mechanism (UNFCCC, 2008) $)^{13}$ suggest that it will be possible to credit

\footnotetext{
${ }^{13}$ Beside sectoral crediting, sectoral targets are also discussed in the negotiations. The difference between crediting and targets is that the latter lead to the issuance of allowances ex ante and imply compliance, while the former within a sectoral crediting mechanism are issued ex post.
} 
emissions reductions from a covered sector against a threshold below the business-as-usual scenario. Thresholds represent country performance and can be expressed in absolute terms (e.g. GHG emissions in sector $\mathrm{x}$ ) as well as intensity terms (e.g. GHG emissions/ton of cement). Sectoral crediting is different from CDM, as credits would be issued to the respective developing country Government, who would have to provide the incentives for emissions reductions to take place. Sectoral crediting based on no-lose targets ${ }^{14}$ aims to encourage emissions reductions (orchestrated by the host country) in key emitting sectors in developing countries.

A technical merit of sectoral crediting is its circumvention of the additionality test on a project basis and reduction of the methodological requirements for assessments for baselines and leakage. Sectoral crediting assesses the performance of a whole sector instead of individual activities, although monitoring will still need to be performed at an installation level for aggregation into a sector level. If this approach can be developed, it has great potential for the transport sector, but establishing full sectoral emissions inventories or sectoral benchmarks is likely to be a challenge (Bongardt et al., 2009).

The suitability of a sectoral approach for the transport sector was reviewed by Bodansky (2007), Meckling and Chung (2009), Schmidt et al. (2008), and Wittneben et al. (2009). Most of them focus on the sector-wide measures related to fuel economy, ignoring possible demand reduction-oriented mitigation strategies (Huizenga et al., 2010). There is limited discussion on how measures aimed at reducing the need for travel or modal shift can be incorporated into a sectoral approach. ${ }^{15}$ There is also little discussion on transport sub-sectoral approaches, such as freight, where some of the methodological concerns on baseline and project boundaries could be more easily overcome because of the more homogenous character of this sub-sector and better data collection practices.

Sectoral crediting has the potential to greatly increase the supply of credits. This may result in a downward pressure on credit prices if the supply is not matched by demand from increased mitigation targets of developed countries. Together with the methodological complexities, the political feasibility of sectoral approaches are the main obstacles, as developing countries may perceive this approach as an indirect way of imposing some sort of emissions commitments.

\subsection{Nationally appropriate mitigation actions (NAMAs)}

Paragraph 1(b)(ii) of the Bali Action Plan (UNFCCC, 2007) calls for: "Nationally appropriate mitigation actions by developing country Parties in the context of sustainable

\footnotetext{
${ }^{14}$ No-lose targets: no penalty applies if the threshold is not met.

15 An exception being the studies on sectoral crediting carried out by Ecofys, see www.sectoral.com.

(C) 2010 The Authors. Natural Resources Forum (C) 2010 United Nations
}

development, supported and enabled by technology, financing and capacity building, in a measurable, reportable and verifiable manner." The Copenhagen Accord (UNFCCC, 2009b) includes similar language. While for mitigation the main current role of developing countries in the Kyoto Protocol is as host countries in the CDM, the adoption of the NAMA concept would introduce a new form of developing countries' participation in global climate governance. Mitigation by developing countries is a key topic of the UNFCCC post-2012 climate regime discussions and, to a large extent, focuses on NAMAs, which indicates the significance of the concept. The discussions within the UNFCCC on NAMAs take place mostly in the Ad-hoc Working Group on Long-term Cooperative Action (AWG-LCA).

There is still a significant lack of clarity on the manner in which NAMAs will be designed, reviewed, implemented and monitored. Some of the key features of the NAMA concept are briefly discussed below, mainly based on the UNFCCC (2009a; 2010a). First, the Bali Action Plan is explicit that NAMAs will be implemented in the context of sustainable development. Yet, little discussion has been conducted on how this can be best accomplished. NAMAs are intended to be country driven and appropriate for the specific national context of the country where they are situated, and may be connected to Low Emission Development Plans (CEC, 2009). Second, it is accepted so far that a NAMA can be a policy, a programme or a project. Most of the NAMA proposals submitted to the UNFCCC after COP15 are described at the sectoral level, mostly without any specification on whether the NAMA will be implemented at the national or the local or city level (UNFCCC, 2010b). The general understanding so far is that NAMAs are not restricted to investment activities which directly reduce GHG emissions but that they can also include actions that will facilitate or enable the reduction of GHG emissions, such as capacity-building or training. Third, three types of NAMAs are generally distinguished: (a) unilateral NAMAs, which are implemented on a voluntary basis and which developing countries are expected to implement without external support; (b) supported NAMAs, which are to be supported and enabled by technology, financing and capacity-building in a measurable, reportable and verifiable manner; and (c) credited NAMAs, in the case of these NAMAs, emissions reductions can become part of a market mechanism like the CDM (UNFCCC, 2009b; 2010a). The international discussion has so far focused mostly on supported NAMAs. Fourth, it is intended that NAMAs would be registered in a NAMA registry. The registration process would include the amount of emissions reductions estimated to be accomplished through the NAMA. The NAMA registry would also record the external support provided for the implementation of the NAMA. The Copenhagen Accord includes an Annex in which developing countries can inscribe their proposed NAMAs. As of September 2010, 42 countries have done so (UNFCCC, 
2010b). Fifth, NAMAs may be supported and enabled by technology, financing and capacity-building, in a measurable, reportable and verifiable manner. Few details are available on the manner in which the NAMAs will be financially structured. Is there a linkage between the financial payment and the amount of GHG emissions reduced under NAMAs? Will payments related to NAMA support be made up front, ex post or on an annual basis? Apart from a reference in the AWG-LCA draft text to the principle of "full incremental costs" as the basis for NAMA support (UNFCCC, 2010a) little is known. Finally, NAMAs and support need to be measurable, reportable and verifiable (MRV) in order to create transparency and trust between developed and developing countries, to ensure that the support is delivered and used for the purpose it was intended for, and to monitor the progress towards the ultimate objective of the UNFCCC, i.e. reducing GHG emissions so that dangerous human interference with the climate is prevented. In addition, MRV can be important for sharing experiences about best practices and creating incentives for action (Bakker et al., 2010b). A proper system of MRV is therefore of high importance. However, the bar for supported and unilateral NAMAs might be placed lower than in the case of CDM because under supported NAMAs there would be no emissions reductions generated to be counted as offsets for developed country emissions. MRV can focus on different aspects of mitigation actions (based on Neuhoff et al., 2009; Jung et al., 2010), including: input, e.g. the financial resources used to implement a policy; the process of developing a policy, e.g. development of a Low Carbon Growth Plan; outputs, which are a direct result of a policy, e.g. increased consumption of renewable energy; outcome, which relates to policy objectives, e.g. GHG emissions reductions.

Heavy emphasis has been placed, especially by the developing countries, on the need for NAMA-related funding to be predictable, measurable, reportable and verifiable. Also, mitigation funding should be clearly separated from - and additional to - development assistance. In the Copenhagen Accord, US\$ 30 billion of additional financing has been promised by developed countries for adaptation and mitigation in developing countries for the period 2010-12, and US\$ 100 billion per year in 2020 (UNFCCC, 2009b). It is not clear from what sources this funding will come or how the funding could be delivered, though a Copenhagen Green Climate Fund is mentioned. ${ }^{16}$ Considering the emerging consensus on the definition of NAMAs that appears to indicate that funding would be available, under supported NAMAs, for both

\footnotetext{
${ }^{16}$ The United Nations Secretary-General created a high-level Advisory Group on Financing that is conducting a study of various funding options. See http://www.un.org/wcm/content/site/climatechange/pages/ financeadvisorygroup for further details.
}

emissions reduction and enabling activities, ${ }^{17} \mathrm{a}$ different disbursement mechanism will have to be found than the one used for CDM.

\subsection{NAMAs in the transport sector: Proposed framework}

Even though the specifics of NAMAs are not yet known, they have been mentioned as having significant potential for reducing transport emissions in developing countries (CCAP, 2010; Dalkmann and Binsted, 2010). In their NAMA proposals for the Copenhagen Accord Annex II, many developing countries have included the transport sector. As of February 2010, 16 out of 25 submissions explicitly included the transport sector. A range of actions is proposed, including infrastructure development, energy efficiency, biofuels, electric vehicles, fiscal incentives and regulatory measures (Dalkmann and Binsted, 2010). The submissions do not provide details on how these actions are going to be implemented.

Policy-based, supported NAMAs would have many similarities with programmatic approaches applied in development assistance by Multilateral Development Banks. International decisions on structuring NAMAs could therefore evaluate such already existing experiences in support of the detailed modalities and procedures for NAMAs.

\subsubsection{Framework for supported NAMAs in the transport sector}

Drawing on experiences with existing instruments (CDM, GEF and CTF) and recent literature, in the following section we discuss a possible way forward for supported NAMAs in order to be successful in catalyzing a shift towards low-carbon sustainable transport. We focus on supported NAMAs. Credited NAMAs may not have great potential, as these are likely to face similar problems as transport projects under the CDM. Unilateral NAMAs fall outside the scope of the paper, which focuses on a review of external climate financing instruments because, by definition, unilateral NAMAs will not be entitled to external support. This does not mean that the potential impact of unilateral NAMAs will be smaller than that of supported NAMAs. Huizenga et al. (2010) observe that the impact of currently unreported domestic actions will remain the most important in terms of GHG reductions, notwithstanding increased involvement of other instruments.

\subsubsection{Scope}

IEA/OECD (2009) conclude that all types of mitigation activities in the transport sector grouped in Section 1 under Avoid-Shift-Improve may be required to achieve low-

\footnotetext{
17 Those activities that do not reduce emissions by themselves, but which are required to successfully implement mitigation actions, such as institutional reform, capacity-building and data gathering.
}

(C) 2010 The Authors. Natural Resources Forum (C) 2010 United Nations 
carbon transport and therefore a framework for transport NAMAs needs to enable the full range of possible interventions.

CCAP (2010) distinguishes three broad categories of potentially eligible supported NAMAs: (1) planning and research activities that support mitigation actions, such as national or subnational low-carbon transportation plans, public outreach, development of models, travel surveys or economic studies; (2) regulation and policy development, such as fuel standards, parking policies, congestion pricing and removal of subsidies; and (3) physical and technical infrastructure, such as bus rapid transit systems, bicycle lanes, biodiesel refineries or the transfer of intellectual property rights.

Jung et al. (2010) suggest single NAMAs need to be embedded in a sectoral strategy, which sets an overall course of action, in order to make sure different measures are compatible and enhance each other. This follows the approach of the CTF, which also attaches a high priority to a sector wide approach. This is an attractive argument for the transport sector, where a range of different measures are necessary in order to achieve the objectives (e.g. parking policies need NMT and public transport incentives as well as awareness-raising to be effective). It may depend on the local context whether it is required to have a sectoral strategy at the national level in order to have an effective transport NAMA or whether an integrated strategy at the city level could also establish such policy coherence and support. Alternatively, sectoral NAMAs can also cover the transport sector (or a sub-sector) of a country, region or city, in which a bottom-up analysis is undertaken to develop a GHG emissions (intensity) baseline and financing is allocated relative to achieving reductions below the baseline, irrespective of the policies implemented to achieve the reductions.

NAMAs by definition will have to be appropriate to the national context, yet many transport NAMAs aimed at improving transport systems are most likely to be local ${ }^{18}$ level NAMAs while transport NAMAs aimed at influencing standards and technology dissemination will more likely be at the national level.

\subsubsection{Criteria for assessment of supported NAMAs}

How can a limited amount of finance, technology and capacity-building be allocated to potentially competing proposals from developing countries? All three types of support are likely to be important for NAMAs in the transport sector, and the type and extent of support can be included in the submission of a NAMAs proposal.

Cost-effectiveness, as calculated by dividing the full incremental cost of an action by the total GHG reduction over the lifetime of the action, is a logical criterion from the point of view of getting the largest amount of atmospheric

\footnotetext{
${ }^{18}$ Local level NAMAs are also "nationally appropriate", and may not be fundamentally different from actions at the sectoral level, apart from having a smaller scale.
}

benefits against lowest cost. However, for the transport sector, the simple concept of cost effectiveness has limited value due to a number of factors. ${ }^{19}$ Cost-effectiveness cannot be quantified with a high degree of certainty. Some actions produce only indirect benefits, such as enabling activities, even though these are necessary for other measures to take effect. Co-benefits for e.g. local air quality or reduced congestion are not taken into account, giving a skewed picture of costs and benefits. Many measures can be considered no-regret options, particularly when co-benefits for air quality are taken into account (Johnson et al., 2009) but do not get implemented due to other barriers. In many cases, up-front costs for investments in infrastructure are high and the (monetary) benefits will only be reaped in the longer term. In order to achieve deep cuts in emissions, transformational measures (e.g. infrastructure for electric vehicles or a change in spatial planning) are required. Climate finance is only a small part of the total investment in the transport sector. In order to make a difference, it needs to catalyze a redirection of business-as-usual investment towards low-carbon transport.

The attractiveness of a (sub)-national transport NAMA would increase if it were to have provisions promoting the replication or scaling up of the NAMA that would in turn trigger further emissions reductions. This would be equivalent to the indirect emissions of GEF projects and the transformational impacts of CTF Projects.

\subsubsection{Acknowledgement of co-benefits}

Important policy goals associated with transport projects, apart from GHG reductions, are: congestion reduction, road safety and air quality. Co-benefits often play a decisive role in determining whether a measure with a certain GHG emissions reduction potential will be implemented or not. In addition, the co-benefits to be realized can influence the scale of a programme. It is increasingly acknowledged that it is important to recognize the co-benefits associated with projects, either qualitative or in quantitative terms.

A full acknowledgement of co-benefits needs to go beyond mere recognition and should include a certain reward for realizing co-benefits. This can be achieved by making the amount of financial support contingent on the degree to which co-benefits are realized. This additional support can be justified based on the likely indirect GHG impact the action would have due to its replication potential. It would not affect the environmental integrity of the NAMA, as the amount of GHG emissions reduced and reported for inclusion in the NAMA registry maintained by UNFCCC would remain the same. This could help ensure that the transport sector participates fully in NAMAs.

If co-benefits are to be recognized and rewarded in transport NAMAs they need to be part of the MRV of the

\footnotetext{
$\overline{19}$ Based on CCAP (2010).
} 
NAMA, which means that they need to be part of the ex ante, the intermediary and the ex post MRV framework (see below).

\subsection{5. $M R V$}

Assessment of GHG emissions under the MRV for transport NAMAs could consist of a combination of bottom-up modelling, based on the ASIF concept (see section 1), and top down approaches, e.g. fuel sales. A particular problem for transport NAMAs, especially for bottom-up modelling, is the requirement for data. In many cases, such data will not all be available at the start of a project and many assumptions will need to be made. To address the data problem, consideration could be given to the use of default values to describe the impacts of certain interventions. Lessons can be learned from the GEF GHG manual for transport which, as stated, will most likely include default values. This leaves a serious question as to whether a methodological approach with so many uncertainties can be used for arriving at a reliable estimate of emissions reductions if these are expected to be less than $10 \%$ below the business-as-usual scenario. ${ }^{20}$

MRV of sector-NAMAs based on proposed sectoral emissions baselines circumvents some of these methodological problems, as the baseline could be compared directly to a single output parameter of GHG emissions, derived from e.g. fuel sales. The difficulties are, to some degree, shifted to the setting of an acceptable reference baseline in the prior proposal stage of the NAMA (Jung et al., 2010).

Given the complexity of GHG MRV, other options for indicators or metrics could be considered. This could also help to address the time lags that occur in several cases before measures are effective in reducing emissions (e.g. Jung et al., 2010). These alternative metrics would include output indicators - such as number of vehicles, share of biofuel in the mix, modal split, quantity of infrastructure built - or process indicators — such as existence of transportation planning. For each type of action, suitable indicators could be developed that would together define the impact of the transport NAMAs. This approach would require an internationally established consensus on the existence of causal linkages between specific indicators and possibly also on the expected quantified GHG emissions reductions in specific operational conditions. In this regard, the experiences from the CDM can be taken into account and the application of the GHG methodologies developed by the GEF and the CTF, which are simpler to use and include default emissions factors. An important step towards further operationalizing the application of different indicator types would be to set up an international database of transport projects and their estimated GHG impacts.

\footnotetext{
${ }^{20}$ The US Department of Transport (2010) estimates that many of the possible mitigation strategies in the transport sector will, in the short to medium term, have emissions reductions of less than $10 \%$.
}

Such an approach would most likely make it easier to integrate the MRV for capacity-building support and technology transfer, in an overall MRV framework, for transport NAMAs. Further, the building of a data-gathering capacity could be considered for inclusion in a NAMA.

\subsubsection{Institutions}

The institutional structure for NAMAs is still evolving, both at the national and the international level. From the perspective of the transport sector, it is important that future NAMA design adequately acknowledges and addresses the multi-sectoral character of the transport sector that will require well-defined institutional coordination mechanisms. Local governments in most developing countries are responsible for the development and management of the transport sector. The future institutional structure for NAMAs will need to reflect these institutional mandates and support actions at both national and local level.

The final design of the MRV framework for transport NAMAs will have its implications for the international institutional framework. Apart from the regular review function of NAMA proposals, there is expected to be a need for a panel of experts who would regularly review default values, if an MRV framework composed of bottom-up modelling based methodologies is adopted. If an MRV framework is chosen that makes use of output or process indicators, an expert panel will be needed in this case as well to determine acceptable indicator categories and to determine their relative weight.

\subsubsection{Financing}

Similar to the "allocated demand" principle described above for $\mathrm{CDM}$, the international climate community could consider allocating a specific portion of future NAMA funding to the transport sector. The Bellagio Declaration on Transportation and Climate Change and CCAP (2010) propose a specific window within the funds for transport, in order to ensure that the sector does not get crowded out due to competition with other sectors. GEF is already making use of sectoral allocations under its different Strategic Programs.

NAMA financing will only cover a small part of the cost of individual programmes or projects to which transport NAMAs will contribute. Based on an assessment of current financing structures for transport in developing countries, Huizenga (2010) concludes that the contribution of climate finance to the development of sustainable, low carbon transport in developing countries is likely to be modest compared to other financing sources. The largest source of funding will be domestic financing from the public and private sector in developing countries. The second largest source of funding will be the Multilateral Development Banks, several of which will increase their funding for transport significantly in the coming years.

The impact of providing, in overall terms, limited climate finance through NAMAs will not substantially alter the 
trajectory of GHG emissions in the transport sector. This means that the overall impact that NAMA funding could have in the transport sector depends on how much it can leverage other financial flows, particularly domestic financing. NAMAs will therefore have to ensure that activities supported in the transport sector address barriers which might prevent the replication and scaling up of the activities supported through it. Equally important is to come to an agreement on how the objectives of climate instruments can complement objectives for other funding streams in the transport sector and how impact assessment methodologies can be harmonized.

\section{Conclusions}

Existing international instruments supporting GHG emissions reductions in the transport sector in developing countries include the Clean Development Mechanism, Global Environmental Facility and the Clean Technology Fund. Emissions reductions resulting from these mechanisms have been very modest, compared to the sectoral share in emissions and considering the need to achieve significant reductions below business-as-usual levels by 2020 and beyond. We conclude that the CDM is not likely to play a large future role, although there may be scope for a bigger share of transport projects than is currently the case. The CTF aims to be a temporary financing instrument compatible with the UNFCCC objective, until a new financing mechanism is operational. This is a key issue in the light of the funding promised by developing countries for mitigation and adaptation in developing countries.

Our second conclusion is that nationally appropriate mitigation actions supported by finance, technology and capacity-building have the potential to generate greater emissions reductions than the existing instruments. In order to achieve this, a special "transport window" in the support for NAMAs would be beneficial, to alleviate the danger that the sector gets crowded out due to competition with other sectors. Second, the scope, design and procedures for transport NAMAs need to: (a) include finance, capacity-building and technology transfer support to enable mitigation activities which help to avoid future transport emissions; (b) shift transport activities to the most efficient mode, and improve the vehicle technology and fuel quality; (c) support national, sub-national and sectoral level actions; (d) provide for MRV arrangements which enable the transport sector to have unfettered access to NAMA funding. This can mean that MRV frameworks focus less on quantified emissions reductions, calculated through modelling, and that MRV frameworks consisting of indicators focusing on the assessment of implementation and progress of the action are considered. In all cases it is important that MRV frameworks allow for relatively large uncertainty in measuring of GHG impacts; (e) recognize and reward co-benefits with the aim of increasing replication and scaling-up of NAMAs. This could be part of a general strategy to reward NAMAs with a high scaling up potential or replication capacity.

Our third conclusion is that, in light of the relatively limited contribution of climate financing to the overall financing of transport programmes and projects, it is important to ensure that the objectives of different climate finance instruments are mutually supportive and that they complement the objectives of other non-climate funding sources. If the specific MRV frameworks for climate finance instruments are compatible with the overall planning and monitoring approach for transport programmes and projects, it will increase the opportunities for the effective deployment of climate finance instruments in the transport sector.

Our final message is: keep it simple.

\section{Acknowledgement}

This article has been written as part of a research project on the applicability of post-2012 Climate Instruments for the Transport Sector. We want to thank the Asian Development Bank and the Inter-American Development Bank for providing funding, inputs and feedback. This article has also benefited from inputs from the Transport Research Laboratory, Ecofys, Wuppertal Institute and EMBARQ The WRI Center for Sustainable Transport. We finally thank Maria Cordeiro, Ko Sakamoto, Christian Ellermann, and Urda Eichhorst for their feedback on a draft version of this article, and the three anonymous reviewers for their comments.

\section{References}

ADB and CAI-Asia, 2010, forthcoming. Rethinking Transport and Climate Change. ADB Sustainable Development Working Paper Series, Asian Development Bank, Manila.

Bakker, S., Haug, C., van Asselt, H., Saïdi, R., Gupta, J., 2010a. Future of CDM: same same but differentiated? Climate Policy, 10, forthcoming.

Bakker, S., De Vita, A., Olivier, J., 2010b. Measuring and reporting emissions and reductions in the post-2012 regime. Netherlands Environmental Assessment Agency WAB report 5000102034, forthcoming.

Barías, J., Browne, J., Sanhueza, E., Silsbe, E., Winkelman, S., Zegras, C., 2005. Getting on track: Finding a path for transportation in the CDM, International Institute for Sustainable Development, Winnipeg, Canada.

Bellagio Declaration on Transportation and Climate Change. Available at: http://www.sutp.org/bellagio-declaration.

Bodansky, D., 2007. International sectoral agreements in a post-2012 climate framework, Working Paper Prepared for the Pew Center on Global Climate Change, Pew Center, Washington DC, USA.

Bongardt, D., Sterk, W., Rudolph, F., 2009. Achieving sustainable mobility in developing countries: Suggestions for a post-2012 agreement. Gaia, 18/4: 307-314; available at www.slocat.net.

CEC, 2009. Stepping up international climate finance: A European blueprint for the Copenhagen deal. Commission of the European Communities, COM(2009) 475/3, CEC, Brussels. 
Center for Clean Air Policy, 2010. Transportation NAMAs: a proposed framework. CCAP, Washington.

Chapman, L., 2007. Transport and climate change: a review. Journal of Transport Geography, 15: 354-367.

CTF, 2009a. Clean technology fund investment criteria for public sector operations. Available at: http://www.climateinvestmentfunds.org/cif/ sites/climateinvestmentfunds.org/files/CTF_Investment_Criteria_ Public_Sector_revisedFeb9.pdf.

CTF, 2009b. Clean technology fund result measurement system. CTF/ TFC.3/8. Available at: http://www.climateinvestmentfunds.org/cif/ sites/climateinvestmentfunds.org/files/CTFresultsmeasurement.pdf.

CTF, 2010. Country and regional investment plans. Available at: http://www.climateinvestmentfunds.org/cif/ Country\%20Investment\%20Plans.

Dalkmann, H., Binsted, A., 2010. Copenhagen Accord NAMA submissions implications for the transport sector. Available at: www. transport2012.org.

den Elzen, M., Höhne, N., 2008. Reductions of greenhouse gas emissions in Annex I and non-Annex I countries for meeting concentration stabilisation targets, Climatic Change, 91(3): 249-274.

$\mathrm{GEF}, 2009 \mathrm{a}$. Investing in sustainable urban transport. The GEF experience, GEF, Washington, DC.

GEF, 2008. Manual for calculating GHG benefits of GEF projects: Energy efficiency and renewable energy projects, GEF, Washington, DC.

GEF, 2009b. GEF-5 focal area strategies. GEF/R.5/Inf.21, GEF, Washington, DC. Available at: http://www.thegef.org/gef/node/1974.

Huizenga, C., 2010. Financing of sustainable, low carbon transport in developing countries: Improving existing instruments and creating new instruments, Presentation made at Next Steps after Copenhagen: Opportunities and Challenges in the Transport Sector, Transforming Transportation 2010.Washington, DC, January.

Huizenga, C., Castillo, C.K., Ajero, M., Sanqui, D.C., 2008. The co-benefits approach: an integrated policy response to climate change and development in Asia, in Loh, C. Stevenson, A. and Tay, S. (eds), Climate change negotiations, can Asia change the game, Civic Exchange, Hong Kong.

Huizenga, C., H. Dalkmann, S. Sanchez, 2010. The future climate regime and the transport sector in developing Asia: the importance of local action, Earthscan, London.

IEA/OECD, 2009. Transport, energy and $\mathrm{CO}_{2}$. Moving toward sustainability. OECD, Paris.

Johansson, B., 2009. Will restrictions on $\mathrm{CO}_{2}$ emissions require reduction in transport demand? Energy Policy, 37: 3212-3322.

Johnson, T., Alatorre, C., Romo, Z., Liu, F., 2009. Low-carbon development for Mexico. The World Bank, Washington, DC.

Jung, M., Vieweg, M., Eisbrenner, K., Höhne, N., Ellermann, C., Schimschar, S., Beyer, C., 2010. Nationally appropriate mitigation actions. Insights from example development. Ecofys report. Available at: http://www.ecofys.com/com/publications/brochures_newsletters/ documents/Report_Ecofys_NAMA_overview_ENG_04_2010.pdf (accessed 22 April, 2010).

Metz, B., Davidson, O.R., Bosch, P.R., Dave, R., Meyer, L.A. (eds), 2007. Climate Change 2007: Mitigation. Contribution of Working Group III to the Fourth Assessment Report of the Intergovernmental Panel on Climate Change, Cambridge University Press, Cambridge, United Kingdom and New York, NY, USA.

Karousakis, K., Guay, B., Philibert, C., 2008. Differentiating countries in terms of mitigation commitments, actions and support, OECD/IEA, Paris, France.

Meckling, J O., Chung, G.Y., 2009. Sectoral approaches to international climate policy: a typology and political analysis, Discussion Paper 2009-02, Belfer Center for Science and International Affairs, Cambridge, MA

Millard-Ball, A., Ortolano, L., 2010. Constructing carbon offsets: the obstacles to quantifying emission reductions. Energy Policy, 38: 533 546.
Nemet, G., Holloway, T., Meier, P, 2010. Implications of incorporating air-quality co-benefits into climate change policymaking. Environmental Research Letters, 5(1).

Neuhoff, K. (ed), 2009. International support for domestic climate policies in developing countries. Climate Policy, 9(5), special issue October.

Olsen, K.H., Fenhann, J., 2008. Sustainable development benefits of clean development mechanism projects. A new methodology for sustainability assessment based on text analysis of the project design documents submitted for validation. Energy Policy, 36: 2819-2830.

Replogle, M., Hook, W., 2010. Proposed methodology for calculating GHG benefits of GEF transportation projects. Presentation at workshop: towards measuring GHG mitigation potential of land transportation projects in the GEF, Manila 17-18 February 2011.

Schipper, L., Marie-Lilliu, M., Gorham, R., 2000. Flexing the link between transport greenhouse gas emissions: a path for the World Bank. International Energy Agency, Paris. Available at: www.iea.org/ textbase/nppdf/free/2000/flex2000.pdf.

Schmidt, J. Helme, N. Lee, J. Houdashelt, M., 2008. Sector-based approach to the post-2012 climate change policy architecture, Climate Policy, 8(5): 494-515.

Skeie, R., Fuglestvedt, J., Berntsen, T., Lund, M., Myhre, G., Rypdal, K., 2009. Global temperature change from the transport sectors: Historical development and future scenarios, Atmospheric Environment, 43(39): $6260-6270$.

TRL, 2010. Submission on modalities and procedures for the development of standardized baselines. Available from www.transport2012.org.

UNEP/Risø, 2010. CDM pipeline July 1, 2010. www.cdmpipeline.org.

UNFCCC, 2005. Modalities and procedures for clean development project activities. FCCC/KP/CMP/2005/8/Add.1, Decision 3/CMP.1.

UNFCCC, 2007. Bali Action Plan. FCCC/CP/2007/6/Add.1.

UNFCCC, 2008. Analysis of possible means to reach emission reduction targets and of relevant methodological issues. Technical Paper, FCCC/ $\mathrm{TP} / 2008 / 2$.

UNFCCC, 2009a. Nationally appropriate mitigation actions by developing country parties. Non-paper by the facilitator. Non-paper No. 51. 6 November 2009.

UNFCCC, 2009b. Copenhagen Accord. Decision -/CP.15. Advance unedited version, 18 December 2009.

UNFCCC, 2009c. Item 3 of the provisional agenda: Consideration of further commitments for Annex I Parties under the Kyoto Protocol. $A W G-K P$, 10th Session, Copenhagen, December 2009. FCCC/KP/ AWG/2009/10/Add.3/Rev.3.

UNFCCC, 2009d. Further guidance to the clean development mechanism. Draft decision -/CMP.5, advanced unedited version, www.unfecc.int (accessed 25 January 2010).

UNFCCC, 2010a. Report of the ad hoc working group on long-term cooperative action under the Convention on its eighth session, held in Copenhagen from 7 to 15 December 2009. Advance version. FCCC/ AWGLCA/2009/17, 5 February 2010.

UNFCCC, 2010b. Appendix II - Nationally appropriate mitigation actions of developing country parties. Available at: unfccc.int/home/ items/5265.php.

Unger, N., Bond, T., Wang, J., Koch, D., Menon, S., Shindell, D., Bauer, S., 2010. Attribution of climate forcing to economic sectors. Proceedings of the National Academy of Sciences, 23(107): 3382-3387.

US Department of Transport, 2010. Transportation's role in reducing US greenhouse gas emissions. Report to Congress.

Wittneben, B., Bongardt, D., Dalkmann, H., Sterk, W., Baatz, C., 2009. Integrating sustainable transport measures into the clean development mechanism, Transport Reviews, 29(1): 91-113.

Wright, L, Fulton, L., 2005. Climate change mitigation and transport in developing countries. Transport Reviews, 25(6): 691-717.

World Bank, 2008. Clean Technology Fund. The World Bank, Washington, DC. Available at: http://www.climateinvestmentfunds.org/cif/sites/ climateinvestmentfunds.org/files/Clean_Technology_Fund_paper_ June_9_final.pdf. 